(1)

CrossMark

\title{
Are inhaled corticosteroids prescribed rationally in primary ciliary dyskinesia?
}

\author{
To the Editor:
}

Primary ciliary dyskinesia (PCD) is a chronic suppurative lung disease characterised by abnormal mucociliary clearance due to genetic defects of motile cilia. PCD patients often present with wheeze and many are prescribed inhaled corticosteroids (ICS). However, ICS are not recommended by international treatment guidelines unless patients have co-existing asthma or airway reactivity [1], or asthma/wheeze with reversible bronchial obstruction (BDR) [2]. The aim of this cross-sectional single-centre study was to determine whether ICS prescriptions were targeted appropriately in PCD [3].

99 children with confirmed PCD [4] were included in this study (52 girls, mean \pm SD age $9.9 \pm 4.7$ years), which was performed as a clinical audit project (Royal Brompton Clinical Audit and Service Development, \#000979). Sample size was opportunistic as there were no data to inform a power calculation. Statistical analysis was performed using GraphPad Prism version 5.00 for Windows (GraphPad Software, San Diego, CA, USA) using the Mann-Whitney U-test for continuous variables and Fisher's exact test for nominal variables. A p-value $<0.05$ was considered significant.

We identified patients who were prescribed ICS based on clinic letters at their latest annual assessment between 2014 and 2016, and compared them to the non-ICS control group; we could not define duration of, or adherence to, treatment, and we did not attempt to define treatment response as no formal trials had been done. We retrieved contemporaneous demographic, diagnostic and clinical data from electronic medical records (clinical history of asthma and atopy, family history of atopic diseases, or atopy defined by elevated total $\operatorname{IgE}$ or specific IgE $>0.35 \mathrm{kUA} \cdot \mathrm{L}^{-1}$ to at least one of a standard panel of common inhalant allergens).

$35(35.4 \%)$ patients were prescribed ICS at a median (interquartile range) equivalent daily dose of 500 (400-800) $\mu \mathrm{g}$ beclomethasone. 24 out of 35 were on fixed-dose combinations with long-acting $\beta$-agonists (LABA). Only three patients in the ICS group and one in the non-ICS group had asthma listed as a diagnosis. In 10 out of 35 patients, ICS had been started for recurrent wheeze as per clinic letters; no information as to the indication for ICS was available for the remaining 25 patients. Five patients had a family history of asthma, all of whom were in the ICS group. Patients prescribed ICS were significantly older and had been older at diagnosis (table 1). Caucasian ethnicity was associated with an increased odds ratio of being prescribed ICS (2.4, 95\% CI 1.03-5.7). No ultrastructural defect was more frequent in the ICS group. 49 (51\%) out of 96 were atopic with no significant difference in prevalence of atopy between the ICS and non-ICS groups. Groups did not differ significantly in nasal NO, blood eosinophils, total IgE (kUA. $\mathrm{L}^{-1}$ or $\mathrm{z}$-scores), serum vitamin D (a parameter that has been associated with lung health, particularly in asthma) or forced expiratory volume in $1 \mathrm{~s}$ (FEV1) \% predicted (ALPHA Touch Fleisch Pneumotachograph (Vitalograph, Buckingham, UK), Rosenthal reference equations [5]). We confirmed that reversible airway obstruction is common in PCD [6] (BDR $>12 \%$; National Institute for Health and Care Excellence guidelines, https://www.nice.org.uk), with 16 (27\%) patients having BDR $>12 \%$ but there were no distinguishing features in those with BDR. BDR was not associated with atopy (OR 2.13, 95\% CI $0.5-8.5)$, raised exhaled nitric oxide fraction ( $F$ eNO) (OR 0.9, 95\% CI 0.1-7.7) or being prescribed ICS (OR 2.1, 95\% CI 0.54-8.2). FeNO, a marker of airway eosinophilia, was generally low, as described previously [7], with no significant difference between the groups. 35 patients underwent bronchoalveolar lavage (BAL), 17 of whom had been prescribed ICS at the time of bronchoscopy. Neutrophilia was the most common finding, but BAL eosinophilia was reported in only one patient on ICS and two patients not on

@ERSpublications

ICS are prescribed irrationally in PCD because diagnosing airway eosinophilia and asthma in this setting is difficult http://ow.ly/nrcB30id7Be

Cite this article as: Dehlink E, Richardson C, Marsh G, et al. Are inhaled corticosteroids prescribed rationally in primary ciliary dyskinesia? Eur Respir J 2018; 51: 1702221 [https://doi.org/10.1183/ 13993003.02221-2017]. 


\begin{tabular}{|c|c|c|c|}
\hline Patient characteristics & ICS & No ICS & p-value \\
\hline Patients (male/female) & $35(13 / 22)$ & $64(34 / 30)$ & 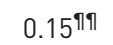 \\
\hline Age years & $13(7.8-15)$ & $9.8(4.9-13)$ & $<0.05^{++}$ \\
\hline Age at diagnosis years & $7.4(3.3-11.2)$ & $2.6(0.3-6.9)$ & $<0.05^{++}$ \\
\hline \multicolumn{4}{|l|}{ Ethnicity } \\
\hline Caucasian & $20(57 \%)$ & $23(36 \%)$ & 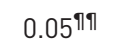 \\
\hline South-East Asian & $7(20 \%)$ & $29(45 \%)$ & \\
\hline Other $\#$ & $7(20 \%)$ & $10(16 \%)$ & \\
\hline Missing data & $1(3 \%)$ & 2 (3\%) & \\
\hline Nasal No" ppb & $75(48-94)$ & $63(37-112)$ & $1.00^{++}$ \\
\hline \multicolumn{4}{|l|}{ Ciliary ultrastructure defect } \\
\hline ODA defect & $13(37 \%)$ & $30(47 \%)$ & \\
\hline IDA defect & 0 & $3(5 \%)$ & \\
\hline ODA+IDA defect & $6(17 \%)$ & $10(15 \%)$ & \\
\hline IDA defect with microtubule disorganisation & $8(23 \%)$ & $5(8 \%)$ & 0.10 กाก \\
\hline Central complex defect & $1(3 \%)$ & $3(5 \%)$ & \\
\hline Normal & $7(20 \%)$ & $13(20 \%)$ & \\
\hline \multicolumn{4}{|l|}{ Atopy $^{+}$} \\
\hline Patients & $21(60 \%)$ & $28(44 \%)$ & $0.21^{\text {กा }}$ \\
\hline Total lgE kUA· $\mathrm{L}^{-1}$ & $86(17-262)$ & $25(13-130)$ & $0.18^{++}$ \\
\hline Blood eosinophils ${ }^{\S} \times 10^{9}$ per $L$ & $0.2(0.2-0.4)$ & $0.2(0.1-0.4)$ & $0.53^{++}$ \\
\hline $\mathrm{FeNO}^{f} \mathrm{ppb}$ & $7(5-10.5)$ & $8(5.3-13)$ & $0.31^{++}$ \\
\hline Serum vitamin $D$ nmol. $\mathrm{L}^{-1}$ & $47(32-57)$ & $55(35-69)$ & $0.25^{++}$ \\
\hline Serum vitamin $D<50 \mathrm{nmol} \cdot \mathrm{L}^{-1}$ & $13 / 23(57 \%)$ & $23 / 52(41 \%)$ & 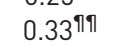 \\
\hline \multicolumn{4}{|l|}{ Spirometry } \\
\hline FEV $1 \%$ predicted & $82(68-88)$ & $81(69-91)$ & $0.64^{++}$ \\
\hline \multicolumn{4}{|l|}{ Reversible airway obstruction } \\
\hline$\%$ change in $\mathrm{FEV} 1$ & $7(2-15)$ & $5.5(1.5-12)$ & $0.43^{++}$ \\
\hline $\mathrm{BDR}>12 \%$ & $7 / 22(32 \%)$ & $9 / 37(24 \%)$ & 0.56 กาก \\
\hline \multicolumn{4}{|l|}{ 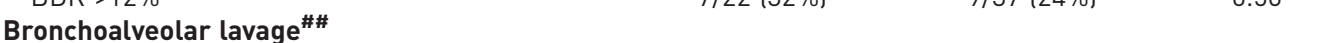 } \\
\hline Eosinophilia & 1 & 2 & \\
\hline Neutrophilia & 11 & 11 & \\
\hline Lymphocytosis & 2 & 1 & \\
\hline Normal differential cell count & 1 & 1 & \\
\hline Differential cell count not performed & 2 & 3 & \\
\hline Lung clearance index & $9.6(8.4-10.9)$ & $7.9(7.2-8.7)$ & $0.06^{++}$ \\
\hline \multicolumn{4}{|l|}{ Chest CT } \\
\hline Normal & 3 & 7 & 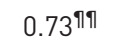 \\
\hline Bronchiectasis & 18 & 30 & \\
\hline
\end{tabular}

Data are presented as median (interquartile range), unless otherwise stated. Non-Caucasian groups were pooled for statistical analysis; inner dynein arm (IDA) defects with microtubule disorganisation have been associated with a more severe clinical course and were compared to all other ultrastructural defects. In the 20 patients whose cilia were normal on transmission electron microscopy, primary ciliary dyskinesia was diagnosed based on genetics and clinical phenotype. ODA: outer dynein arm; FeNO: exhaled nitric oxide fraction; FEV1: forced expiratory volume in 1 s; BDR: bronchodilator reversibility; CT: computed tomography. \#: African, Turkish or mixed; ๆ : $n=56 ;{ }^{+}: n=96 ;{ }^{\S}: n=95 ;{ }^{f}: n=44 ;{ }^{\# \#}: n=35$; ๆๆ: Fisher's exact test; ${ }^{++}$: Mann-Whitney U-test.

ICS. There was no difference between groups in lung clearance index (multiple breath inert gas washout measurements with sulfur hexafluoride) or the prevalence of bronchiectasis on high-resolution computed tomography, both of which are markers of disease severity.

We found that ICS are commonly prescribed in PCD often without evidence of type 2 airway inflammation. There was a high frequency of atopy and reversible bronchial obstruction, which may have suggested type 2 airway inflammation would be common. However, reversible airflow obstruction may be due to mucus shifting, and indeed, the greater bronchodilatation previously reported with exercise rather than a short-acting $\beta_{2}$-agonist supports this view [6]. Objective evidence of type 2 inflammation was scarce: only four patients had positive BDR with evidence of eosinophilia (blood and/or airways), and 
three patients were atopic, had BDR and had evidence of eosinophilia (data available for $\mathrm{n}=57$ ). Airway eosinophilia, a hallmark of type 2 airway inflammation and response to ICS [8], was rare. Patients on ICS were significantly older, and in 20 out of 35 patients, ICS treatment was started prior to being diagnosed with PCD, implying that they had been incorrectly treated as though they had asthma. However, the decision to continue the prescription of ICS may be irrational.

Although ICS are safe, high doses such as were prescribed to many PCD children, carry an increased risk of systemic side-effects, including adrenal suppression and growth retardation [9]. ICS may also cause topical immunosuppression, which could impair airway immune responses [10]. More recently, ICS have been linked with nontuberculous mycobacterial (NTM) lung disease in chronic respiratory diseases [11]. No cases of NTM lung disease were identified in our cohort.

This is the first study assessing ICS prescription in PCD based on individual patient data and the strength of our study is its size: nearly a quarter of all children with a known diagnosis of PCD in England were included. We highlight that ICS are prescribed more frequently in Britain than previously estimated in a questionnaire-based European study [12]. The main weakness is the lack of induced or spontaneously expectorated sputum to classify airway inflammation. We did not measure airway reactivity, as recommended in the American PCD treatment guidelines, but many patients had airflow limitation precluding bronchial challenge testing [13]: 22 out of 83 (27\%) patients had FEV1 $<70 \%$ predicted, 10 $(12 \%)$ of whom had $\mathrm{FEV}_{1}<60 \%$ predicted. In addition, as with BDR, bronchial hyperresponsiveness is not specific for type 2 inflammation [14]. We also acknowledge that we do not have data on adherence to ICS or pre-ICS data on airway inflammation and bronchodilator responsiveness, and we have pooled patients on ICS and combined ICS+LABA, potentially leading to false negative BDR due to LABA action. However, this does not detract from our conclusions, because ICS should be used to target type 2 inflammation, not BDR which is nonspecific. It could be argued that some patients prescribed ICS had had a treatment response and the ongoing prescription was rational. However, without a formal double-blind, placebo-controlled therapeutic trial, placebo effects cannot be excluded, and there is no scientific basis for a beneficial effect of ICS on neutrophilic airway inflammation. Our findings resemble previous practice in cystic fibrosis, where ICS were widely used as anti-inflammatory drugs in an attempt to treat recurrent wheeze but are no longer recommended due to lack of evidence of beneficial effects [15]. In PCD, randomised controlled ICS trials are needed to clarify if they have any role outside treatment of type 2 inflammation.

In summary, ICS are not being used rationally in PCD and ICS prescription is inappropriate in PCD unless there is evidence of type 2 airway inflammation.

Eleonora Dehlink ${ }^{1}$, Charlotte Richardson ${ }^{1}$, Gemma Marsh ${ }^{1}$, Kiralie Lee ${ }^{1}$, Angela Jamalzadeh ${ }^{1}$, Andrew Bush ${ }^{1,2}$, Claire Hogg ${ }^{1}$ and Siobhán B. Carr ${ }^{1}$

${ }^{1}$ Dept of Paediatric Respirology, Royal Brompton Hospital, London, UK. ${ }^{2}$ Dept of Paediatric Respirology, Imperial School of Medicine at National Heart and Lung Institute, London, UK.

Correspondence: Eleonora Dehlink, Royal Hospital for Children, Upper Maudlin Street, Bristol, BS2 8BJ, UK.

E-mail: Eleonora.dehlink@uhbristol.nhs.uk

Received: Oct 282017 | Accepted after revision: Jan 142018

Conflict of interest: S.B. Carr reports receiving personal fees from Vertex Pharmaceuticals and Actavis Pharmaceuticals, and grants and personal fees from Chiesi Pharmaceuticals, outside the submitted work.

Support statement: This study was supported by BMBS COST Action BM1407. Funding information for this article has been deposited with the Crossref Funder Registry.

\section{References}

1 Shapiro AJ, Zariwala MA, Ferkol T, et al. Diagnosis, monitoring, and treatment of primary ciliary dyskinesia: PCD foundation consensus recommendations based on state of the art review. Pediatr Pulmonol 2016; 51: 115-132.

2 Barbato A, Frischer T, Kuehni CE, et al. Primary ciliary dyskinesia: a consensus statement on diagnostic and treatment approaches in children. Eur Respir J 2009; 34: 1264-1276.

3 Pavord ID, Beasley R, Agusti A, et al. After asthma: redefining airways diseases. Lancet 2018; 391: 350-400.

4 Lucas J, Barbato A, Collins S, et al. European Respiratory Society guidelines for the diagnosis of primary ciliary dyskinesia. Eur Respir J 2017; 49: 1601090.

5 Rosenthal M, Bain S, Cramer D, et al. Lung function in white children aged 4 to 19 years: I - spirometry. Thorax 1993; 48: 794-802.

6 Phillips G, Thomas S, Heather S, et al. Airway response of children with primary ciliary dyskinesia to exercise and $\beta_{2}$-agonist challenge. Eur Respir J 1998; 11: 1389-1391.

7 Boon M, Meyts I, Proesmans M, et al. Diagnostic accuracy of nitric oxide measurements to detect primary ciliary dyskinesia. Eur J Clin Invest 2014; 44: 477-485.

8 Berry M, Morgan A, Shaw DE, et al. Pathological features and inhaled corticosteroid response of eosinophilic and non-eosinophilic asthma. Thorax 2007; 62: 1043-1049. 
9 Kapadia C, Nebesio T, Myers S, et al. Endocrine effects of inhaled corticosteroids in children. JAMA Pediatr 2016; 170: $163-170$.

10 Sabroe I, Postma D, Heijink I, et al. The yin and the yang of immunosuppression with inhaled corticosteroids. Thorax 2013; 68: 1085-1087.

11 Andréjak C, Nielsen R, Thomsen V, et al. Chronic respiratory disease, inhaled corticosteroids and risk of non-tuberculous mycobacteriosis. Thorax 2013; 68: 256-262.

12 Strippoli MP, Frischer T, Barbato A, et al. Management of primary ciliary dyskinesia in European children: recommendations and clinical practice. Eur Respir J 2012; 39: 1482-1491.

13 Crapo R, Casaburi R, Coates A, et al. Guidelines for methacholine and exercise challenge testing - 1999. This official statement of the American Thoracic Society was adopted by the ATS Board of Directors, July 1999. Am J Respir Crit Care Med 2000; 161: 309-329.

14 Levine H, Cohen-Cymberknoh M, Klein N, et al. Reversible airway obstruction in cystic fibrosis: common, but not associated with characteristics of asthma. J Cystic Fibros 2016; 15: 652-659.

15 Balfour-Lynn IM, Welch K. Inhaled corticosteroids for cystic fibrosis. Cochrane Database Syst Rev 2016; 8: CD001915. 